\title{
Conversas entre mulheres durante o exame citopatológico
}

\section{Conversations between women during cytopathological exam}

\author{
Stela Nazareth Meneghel \\ (i) https://orcid.org/0000-0002-7219-7178 \\ E-mail: stelameneghelळgmail.com \\ Daniela Pinheiro Andrade \\ (D) https://orcid.org/0000-0003-4580-5307 \\ E-mail: danielanegraes23ळgmail.com \\ aniversidade Federal do Rio Grande do Sul. Escola de \\ Enfermagem. Programa de Pós-Graduação em Saúde Coletiva. \\ Porto Alegre, RS, Brasil. \\ ${ }^{b}$ Pesquisadora independente. Interagis Serviços em Linguística \\ Aplicada. São Leopoldo, RS, Brasil.
}

\section{Resumo}

Este artigo aborda conversas entre enfermeiras e mulheres, durante consultas ginecológicas para realização de exame citopatológico. Trata-se de estudo qualitativo que analisou as conversas produzidas durante consultas realizadas em três serviços de atenção básica de saúde de um município do Sul do Brasil. A análise das conversas entre enfermeiras e mulheres usuárias dos serviços foi pautada na perspectiva teórico-metodológica da fala-em-interação, abordagem em que as categorias não são definidas a priori, mas emergem a partir das interações entre os falantes. Os fenômenos interacionais de interesse são analisados a partir de excertos de conversas entre três enfermeiras e sete das 26 mulheres que buscaram os serviços de atenção básica em saúde, transcritas segundo as convenções adotadas por analistas da conversa. Por meio de análise das categorias de pertença, observou-se que nas conversas as mulheres se identificam de acordo com os papéis tradicionais de mãe e esposa. Enfermeiras e usuárias compartilham a ideia de que a sexualidade dos homens, pautada no biológico, é irrefreável, e acreditam que devem cumprir as obrigações matrimoniais de esposas, atendendo à necessidade sexual dos maridos, mesmo quando sentem desconforto e dor. Os achados desta pesquisa podem auxiliar os profissionais da saúde a refletirem criticamente acerca das interações conversacionais com as usuárias de serviços de saúde.

Palavras-chave: Gênero; Sexualidade; Análise da Conversa; Fala-em-interação.

\section{Correspondência}




\section{Introdução}

This article is about conversations between nurses and women, during gynecological consultations for cytopathological examination. This is a qualitative study that analyzed the conversations made during consultations carried out in three primary health care services of a municipality in the southern Brazil. The analysis of the conversations between nurses and women users of services was based on the theoretical-methodological perspective of speech in interaction, an approach in which the categories are not defined a priori, but they emerge from the interactions among the speakers. The interactional phenomena of interest are analyzed in excerpts from conversations between three nurses and seven of the 26 women who sought primary health care services, transcribed according to the conventions adopted by conversation analysts. Through the membership categorization analysis, one observed in the conversations women identify themselves with the traditional roles of mothers and wives. Nurses and users share the idea that men's sexuality, based on the biological aspect, is unstoppable and believe they must fulfill spousal obligations, meeting the husbands' sexual needs, even when they feel discomfort and pain. The findings of this study may help health professionals to reflect critically on their conversational interactions with health service users.

Keywords: Gender; Sexuality; Conversation Analysis; Speech in interaction.
A consulta ginecológica de enfermagem na atenção básica inclui a coleta de material para a realização do exame citopatológico (CP) e, embora este tipo de consulta constitua um espaço estratégico para ouvir relatos sobre a vida sexual das mulheres atendidas, nem sempre os profissionais abrem espaço para tratar do tema, limitando-se à execução das rotinas padronizadas e pautadas no modelo biomédico (Silva; Gitsos; Santos, 2013).

A saúde sexual e reprodutiva é uma das áreas de atuação prioritárias da Atenção Básica à Saúde (AB) brasileira e, segundo o Ministério da Saúde, a atenção à saúde deve ser ofertada observando-se como princípio o respeito aos direitos sexuais e reprodutivos. Observa-se, porém, que os profissionais de saúde se sentem pouco preparados para lidar com este tema, e as ações, em sua maioria, têm sido focadas na saúde reprodutiva, predominando aquelas voltadas ao ciclo gravídico-puerperal e à prevenção do câncer de colo de útero e de mama (Brasil, 2013).

Entre as dificuldades para as mulheres falarem sobre aspectos relacionados a sua vida sexual, está o modo como ocorre a socialização de gênero, que veicula normas e papéis para o feminino, segundo os quais elas precisam se comportar de acordo com o que é designado a elas na cultura, interditando a fala sobre a vida privada, mesmo quando há insatisfação ou violência.

A conversa entre profissionais de saúde e usuárias de serviços traz a questão da linguagem como elemento reflexivo acerca das práticas de saúde que incidem sobre as mulheres. Cabe citar a contribuição dos estudos de linguistas feministas, como Deborah Cameron (1998, 2005), que trata a linguagem como parte essencial da produção científica crítica elaborada pelas mulheres. A autora atribui às pesquisas acerca da linguagem e do gênero a mudança de concepção de linguagem, e mostra o quanto as conversas tem papel decisivo na constituição de pessoas enquanto sujeitos generificados, realizando um trabalho performativo de gênero, em que a todo momento as pessoas precisam reafirmar suas identidades. No Brasil, as abordagens teórico-metodológicas adotadas pelas linguistas feministas incluem desde a 
sociolinguística interacional, a análise de discurso de linha francesa, a análise crítica do discurso (ACD) e a análise da conversa (Pinto; Badan, 2012).

Os estudos que abordam as relações entre profissionais de saúde e usuários(as) de serviços têm sido agrupados sob a denominação genérica de “estudos sobre a relação médico-paciente", mesmo quando esta relação é ampliada para incluir outros profissionais da saúde e pessoas saudáveis que procuram os serviços de saúde para realizar ações preventivas (Meneghel; Ostermann, 2012).

O estudo da relação médico-paciente ou profissional de saúde-usuário(as), aqui considerados similares, tem sido objeto de crescente interesse em pesquisas e debates, muitos deles preocupados com aspectos práticos das interações conversacionais, que compreendem ou deveriam compreender o diálogo, o acolhimento, a escuta sensível e a construção de vínculo (Alves; Rabelo, 1999; Caprara; Rodrigues, 2004). Esses estudos contribuem não apenas para a prática dos médicos, mas para todos os profissionais do campo da saúde. Para Caprara e Rodrigues (2004), um dos pontos críticos é a verticalidade e assimetria presentes nestas relações, enquanto que Schraiber (1997) pontuou a excessiva especialização e "a crise de confiança” que tem permeado esta relação.

Assumir que a relação entre profissionais e pacientes ou usuários é eminentemente interacional significa que debruçar-se sobre estas conversas permite alargar a compreensão sobre os "fazeres" das práticas clínicas e de atenção à saúde. A vertente adotada pela linguística, por meio da perspectiva teórico-metodológica da análise da conversa (AC), ou teoria da fala-em-interação, estuda as interações que ocorrem durante consultas prestadas por profissionais do campo da saúde (Ostermann; Meneghel, 2012).

Nesse artigo, a fala-em-interação foi utilizada para analisar conversas produzidas entre enfermeiras e usuárias durante consulta ginecológica para coleta de material destinado a exame citopatológico. O objetivo do estudo foi observar e descrever os elementos interacionais nas conversas das mulheres (enfermeiras e usuárias), de que maneira se deram as conversas e que padrões linguísticos foram usados durante as consultas. A ideia era identificar como se dava a relação entre elas, a partir das interações, sem utilizar categorias prévias, mesmo entendendo que questões referentes à sexualidade e à conjugalidade poderiam emergir, na medida em que o desnudamento das mulheres e o foco em um exame de natureza ginecológica poderiam propiciar a fala sobre este assunto.

\section{Percurso metodológico}

Este é um estudo qualitativo pautado na análise da conversa ou teoria da fala-em-interação, que analisou interações entre enfermeiras e usuárias durante a consulta de enfermagem focada na coleta do exame citopatológico. A fala-em-interação observa como se dão as conversas, organizadas em turnos de fala, nas quais se alternam os enunciados dos falantes produzidos em organização sequencial (Loder; Jung, 2009; Sell, 2012).

As pesquisas que utilizam a análise da conversa observam interações naturalísticas, ou seja, conversas que ocorrem em contextos cotidianos, sejam mundanos ou institucionais, como as de consultórios de profissionais da área da saúde. O método não utiliza coleta formal de dados, tais como entrevistas e questionários, e prescinde de categorias pré-estabelecidas, partindo da perspectiva êmica, em que os padrões e categorias são feitos relevantes pelos próprios falantes no contexto interacional (Silva; Andrade; Ostermann, 2009). Nesse sentido, a emersão de categorizações feitas pelas participantes, acerca dos comportamentos que cada sexo deve desempenhar no exercício da sexualidade (Scott, 1990), e a maneira como elas demonstram compreender os direitos e obrigações de um ou outro sexo (biológico) abrem brechas para a análise das interações investigadas sob a perspectiva de gênero. Isso se dá uma vez que os modos pelos quais as pessoas produzem categorizações na linguagem cotidiana permitem entender a percepção de mundo destes falantes.

Para os analistas da conversa, as categorizações de pertença (ACP) referem-se às descrições que as pessoas fazem de si mesmas, incluindo aspectos com que se identificam, relacionados a papéis, funções, gênero, geracionalidade, raça/cor etc. A partir dos estudos da etnometodologia, percebeu-se que na linguagem naturalística as pessoas constroem estas categorizações, sendo que para cada categoria, os e as 
falantes incluem um conjunto ou série de atributos e características (Corona; Ostermann 2012; Sell; Ostermann, 2009, 2012; Watson; Gastaldo, 2015).

As identidades, cujos elementos estão presentes nas categorias de pertença, não são tidas como apriorísticas, fixas ou únicas; elas são constituídas, construídas e negociadas por meio das práticas sociais e discursivas. Os e as participantes, quando descrevem alguém, dão pistas sobre eles mesmos e reafirmam a construção de suas identidades na própria interação social (Ostermann, 2006; Ostermann; Jager, 2012). A escolha de alguns aspectos (e não de outros) de um repertório de identidades e descritores por algum falante revela aquilo que ele ou ela torna relevante no aqui e agora da interação (Schegloff, 2007), já que a categorização é um processo pelo qual os indivíduos produzem ações discursivas e, ao categorizar socialmente uma pessoa ou a si mesmos, estão implícitos julgamentos e avaliações baseados em expectativas socialmente convencionadas (Braga; Gastaldo; Guimarães, 2016).

0 conceito de categoria de pertença refere-se à maneira pela qual os falantes identificam a si e a outros, baseando-se em suposições compartilhadas pelo grupo, fazendo inferências sobre as atividades, direitos, obrigações, motivos e competências vistas como pertinentes à categoria em questão. As relações efetuadas por membros de uma determinada categoria é uma ação conjunta, que inclui para o primeiro falante a realização de práticas entendidas como apropriadas, cabendo para o segundo a ratificação das práticas do primeiro (Pomerantz; Mandelbaum, 2005).

A ação de categorizar é cultural e dinâmica, adquirindo significado de acordo com o contexto, não se tratando de uma "grade cultural inerte" na qual as categorias são inseridas. Essa metodologia de pesquisa, ao buscar entender quando e como os membros fazem descrições, procura identificar os dispositivos pelos quais as descrições são produzidas, remetendo à ideia de "maquinaria" operando por trás da ação de categorizar (Sell; Ostermann, 2012).

Com base nos dados e de acordo com os pressupostos da análise da conversa, procurou-se observar como se deram as tomadas de turnos, a sequencialidade, os silêncios e pausas, a expressão de formulações (quando uma pessoa descreve a ação que ela mesma ou seu/sua interlocutor(a) está realizando), reparos (ação de suspender a contiguidade da conversa para lidar com problemas de fala, entendimento ou audição), justificativas (accounts), atribuições causais feitas pelas participantes da conversa e (des)afiliação (Steensig; Larsen, 2008), um conceito que diz respeito à maneira como o interagente demonstra posicionar-se em relação a algo dito por seu interlocutor. Quando o interagente exibe concordância com a perspectiva demonstrada pelo interlocutor sobre o tópico local e situado na conversa, diz-se que há afiliação interacional. Quando o interagente explicita discordância da posição adotada pelo interlocutor, de modo oposto, diz-se que há desafiliação interacional.

Apareceram temas delicados, aqueles que se referem a assuntos tabus, geram constrangimento e são percebidos na conversa por meio de hesitações, pausas ou silêncios. Além da análise destes padrões, observouse a emergência de categorias de pertença que as participantes mobilizam e, assim, em última instância, demonstram suas posições de gênero, incluindo relatos da vida sexual e das relações de conjugalidade.

Neste estudo, as participantes da pesquisa foram três enfermeiras que atuam em três serviços de $A B$ de um município de médio porte do interior do estado do Rio Grande do Sul e 26 mulheres em idade reprodutiva que procuraram o atendimento de enfermagem para coleta de material para o exame citopatológico.

A produção de dados foi realizada por meio da gravação de interações naturalísticas ocorridas durante consultas de enfermagem para coleta de material para exame $\mathrm{CP}$, realizadas entre enfermeiras e usuárias dos serviços de saúde, no período de março a dezembro de 2016. Obtido consentimento da Secretaria de Saúde local e realizados os contatos nas unidades de saúde, deu-se início ao processo de acompanhamento das consultas. As gravações foram feitas por uma das pesquisadoras, que apresentava a proposta à usuária e solicitava permissão para realizar a gravação da consulta. Só então o gravador era ligado e a pesquisadora permanecia oculta atrás do biombo, sem participar da conversa. Foram gravadas interações referentes ao tempo total da consulta, compreendendo a entrada da usuária na sala, o preenchimento do prontuário, a preparação para o exame, colocação na mesa, coleta do material, orientações e despedida. 
As consultas foram transcritas usando as convenções utilizadas pelos analistas da conversa (Gago, 2002) (Quadro 1). Nos excertos apresentados, as enfermeiras são identificadas como E1, E2 e E3 e as mulheres referenciadas de M1 a M26. Apresentam-se sete excertos de interações referentes às enfermeiras: E1, E2 e E3, profissionais com idades entre 23 e 33 anos; e às usuárias: M1, M5, M9, M10, M15, M22, M23, com idades entre 19 e 62 anos.

Quadro I - Convenções de transcrição

\begin{tabular}{|c|c|}
\hline$(1.8)$ & pausa \\
\hline (.) & Micropausa \\
\hline$=$ & Fala colada \\
\hline [Texto] & Falas sobrepostas \\
\hline , & Entonação contínua \\
\hline 个texto & Entonação ascendente da sílaba \\
\hline$\downarrow$ texto & Entonação descendente da sílaba \\
\hline . & Entonação descendente do turno \\
\hline ? & Entonação ascendente do turno \\
\hline- & Marca de interrupção abrupta da fala \\
\hline$:::$ & Alongamento de som \\
\hline$>$ Texto $<$ & Fala acelerada \\
\hline$>>$ Texto $<<$ & Fala muito acelerada \\
\hline$<$ Texto $>$ & Fala lenta \\
\hline$<<$ Texto $>>$ & Fala muito lenta \\
\hline TEXTO & Fala com volume mais alto \\
\hline${ }^{\circ}$ texto ${ }^{\circ}$ & Volume baixo \\
\hline${ }^{\circ}$ texto $^{\circ \circ}$ & Volume muito baixo \\
\hline Texto & Sílaba, palavra ou som acentuado \\
\hline (Texto) & Dúvidas da transcritora \\
\hline$x \times x x$ & Fala inaudivel \\
\hline$(($ Texto $))$ & Comentários da transcritora \\
\hline hhhh & Riso expirado \\
\hline hahahehehihi & Risada com som de vogal \\
\hline$\{\{$ rindo $\}$ texto $\}$ & Turnos ou palavras pronunciadas rindo \\
\hline .hhh & Inspiração audível \\
\hline
\end{tabular}

Modelo baseado nas propostas Jefersonianas de transcrição e adaptado pelo grupo Fala-em-interação em Contextos Institucionais e Não-Institucionais (FEI) com marcações sugeridas pelo GAT2.

Este trabalho foi aprovado em Comitê de Ética em Pesquisa e as observações e gravações das consultas foram realizadas com o consentimento formal de todas as participantes.

\section{Vida sexual e conjugalidade na fala das mulheres enfermeiras e usuárias}

Na sociedade patriarcal, a diferenciação entre os sexos é mantida por meio de hierarquias de poder entre homens e mulheres e implica em subordinação das mulheres (Scott, 1990). Essas hierarquias são assimiladas por meio da socialização de gênero, em que as palavras assumem uma função crucial, e as diferentes instituições sociais, incluindo os serviços de saúde, encarregam-se da veiculação do que é esperado para cada um dos sexos.

Nesse estudo, nas falas que constituíram as consultas investigadas, percebemos as hierarquias entre homens e mulheres presentes em referências sobre desempenho da sexualidade, estereótipos e papéis sexuais, o que nos levou a utilizar a análise de categorias de pertença (Schegloff, 2007; Sell; Ostermann, 2009, 2012) para estudar as categorizações expressas na fala das mulheres que fizeram parte da observação - enfermeiras e usuárias. Vale destacar que, apesar das diferenças geracionais, culturais e de classe social, as mulheres participantes do estudo demonstram partilhar expressões circulantes na cultura alinhadas às normas hegemônicas para a sexualidade e papéis sexuais, nas quais adquiriu relevância o desempenho dos papéis sociais de esposa e mãe.

As categorias de pertença acionadas nas conversas entre enfermeiras e usuárias estão impregnadas pelo padrão heteronormativo, que vigora na sociedade do interior do Rio Grande do Sul, em que a heterossexualidade é considerada um princípio organizador na sociedade e opera como uma grade cultural pela qual os corpos e os gêneros são naturalizados. A heteronormatividade é um sistema que propugna uma sexualidade monogâmica e voltada à procriação, o binarismo biológico homemmulher, a complementariedade dos papéis sexuais e a organização tradicional da família. Essa concepção não constitui algo abstrato, mas uma ideologia materializada, presente em situações de fala-eminteração, ainda que muitas vezes não percebida pelos interagentes (Butler, 2007; Cameron, 2005; Ostermann; Jager, 2012).

As concepções de gênero tradicionais, baseadas em características atribuídas ao feminino, ainda 
estão presentes na atualidade, tanto na fala das profissionais quanto na das usuárias, conforme torna-se evidente no Excerto 1:

\section{Excerto I- 19 anos, ensino fundamental, união estável, 2 filhos}

\begin{tabular}{|c|c|c|}
\hline 2 & E3: & $\begin{array}{l}\text { aí assim b. tu vai pass- >>tu pode }<<\text { passá aqui } \\
\text { comigo (0.5) aqui atrás aí tu vai tirá a parte de } \\
\text { baixo }\end{array}$ \\
\hline 4 & & $(0.5)$ \\
\hline 5 & E3: & $\begin{array}{l}\text { conforme eu fazê o exame eu vou te } \\
\text { explicando mas é bem tranquilo }\end{array}$ \\
\hline 7 & Mi5: & tá \\
\hline 8 & E3: & é bem (.) tranquilo \\
\hline 9 & Mi5: & é né hhh \\
\hline 10 & & $(20.9)$ \\
\hline 11 & E3: & senta bem aqui na pontinha e tira a calcinha ( 0.7$)$ \\
\hline 13 & & fica tranquila que é tudo mulher aqui (0.6) \\
\hline 16 & Mi5: & hhh ah mas a gente fica meio assim \\
\hline
\end{tabular}

"Fica tranquila, é tudo mulher aqui" (excerto 1, linha 13), recomendação da profissional à usuária após ter-lhe solicitado que tirasse a calcinha e sentasse na beirada da maca, demonstra como concepções homogêneas - por exemplo, de sexualidade - são tacitamente acionadas e tomadas como certas nas interações em análise. Em última instância, a maneira como a categorização "mulher" é mobilizada no contexto interacional do aqui e agora, nessa interação exclui toda e qualquer possibilidade de comportamento para além do padrão heteronormativo e suas consequências para a construção essencialista de gênero. Contudo, em oposição à identidade feminina coletiva e homogênea acionada pela enfermeira para "tranquilizar" a usuária, M15 recoloca o foco no plano individual e indica que não se tranquilizou com a fala genérica da enfermeira, "ah mas a gente fica meio assim" (linha 16), deixando transparecer que "estar entre mulheres" não assegura isenção de constrangimentos, independentemente de a causa desse sentimento ter ligação direta ou não com a sexualidade das participantes.

Outra dimensão do significado de ser mulher para a enfermeira referida nos dados como E3 emerge no Excerto 2, dessa vez ligada a um feminino construído para a aceitação do sofrimento:
Excerto 2-34 anos, ensino fundamental, união estável, 2 filhos

\begin{tabular}{|c|c|c|}
\hline 1 & E3: & $\begin{array}{l}\text { mulher né (0.5) é um saco a gente tem que } \\
\text { passá por isso }\end{array}$ \\
\hline 3 & & $(0.7)$ \\
\hline 4 & E3: & pode ir pra trás \\
\hline 5 & & $(1.6)$ \\
\hline 6 & E3: & $\begin{array}{l}\text { se tu conseguir ir um pouquinho isso assim } \\
\text { pra baixo tá bom }\end{array}$ \\
\hline 8 & & (.) \\
\hline 9 & E3: & tem que passá por isso não tem \\
\hline 10 & & (.) \\
\hline 11 & M22: & tem que fazê não adianta \\
\hline
\end{tabular}

Na linha 1, E3 aciona a categorização mulher ao fazer uma reclamação atrelada à "obrigação" do procedimento de coleta de material para exame CP - "Mulher né, é um saco a gente tem que passar por isso". Vê-se que a reclamação de E3 ancora-se na resignação em relação ao sofrimento que faz parte do feminino, que pouco vale - "é um saco" - e que não tem possibilidade de mudança, aspecto que é retomado na linha 9 - "tem que passá por isso, não tem". A usuária, por sua vez, demonstra alinhamento ao entendimento de $\mathrm{E}_{3} \mathrm{e}$, portanto, conformidade e aceitação da inevitabilidade da realização do exame - "tem que fazê [o exame ginecológico] não adianta”. Dessa forma, ambas, enfermeira e usuária, demonstram compartilhar do ideário local atrelado à relevante categorização de mulher feita na interação, qual seja, a de que a mulher está fadada ao sofrimento e que aceitá-lo faz parte da natureza feminina.

Apesar de as políticas de atenção às mulheres preconizarem a integralidade, ainda se observa, nos serviços de saúde e na voz dos profissionais, a manutenção da perspectiva materno-infantil na qual o feminino fica menorizado e restrito às identidades de mãe ou esposa. A esta perspectiva soma-se o estereótipo da mãe sofredora e do parto como um momento inesquecível, mais pela dor do que pela alegria. No excerto 3, apresentado a seguir, a enfermeira, ao instruir a usuária para posicionar-se na mesa, solicita confirmação sobre seu conhecimento referente à posição ginecológica clássica, "a senhora lembra a posição de ganha nenê?” (linhas 1 e 2), ao que M1o responde afirmativamente: 
Excerto 3- 62 anos, ensino fundamental incompleto, separada, 9 filhos

$\begin{array}{lll}\text { I } & \text { E2: } & \begin{array}{l}\text { i:sso (.) vamo subi a } \uparrow \text { qui (.) a senhora } \\ \text { 个lembra a posição do-de }\end{array} \\ 2 & & \text { a posição do- de ganhá nenê? } \\ 3 & \text { Mı: } & \text { 'sim }{ }^{\circ} \\ 4 & \text { E2: } & \text { é a mesma né } \\ 5 & \text { Mı: } & \text { Ahã } \\ 6 & \text { E2: } & \text { essa aí não dá pra esquecê [né] } \\ 7 & \text { MıO: } & \text { [não] dá pra esquecê }\end{array}$

Após a confirmação de M1o, na linha 3, há uma nova sequência de confirmação de reconhecimento da posição ginecológica clássica (linhas 4 e 5) e, em seguida, E2 faz uma avaliação (linha 6) acerca de seu caráter inesquecível, ao que Mio se alinha - "não dá pra esquecê" (linha 7). Nesse aspecto, a repetição de M1o, em fala colada à da enfermeira, remete ao que afirma Souza (2009), isto é, repetições parciais de turno podem ocorrer quando a(o) ouvinte compartilha da asserção e concorda com ela, alinhando-se, assim, ao que foi dito anteriormente. Observa-se que o referente em pauta parece remeter ao sofrimento ligado ao feminino, não havendo referência, em contraposição, ao prazer proveniente da atividade sexual, que poderia ser relacionado à posição em questão.

Ainda com relação ao modo como a coleta de CP é realizada interacionalmente no aqui e agora, é notável que as enfermeiras, ao mesmo tempo em que examinam e coletam o material, vão relatando o que estão fazendo e/ou observando. Assim, com base nos dados, percebe-se haver ocorrência de padrões interacionais ao que se segue à atividade de observação da parede interna da vagina. Em se tratando de mulheres na menopausa, ou mesmo jovens, as enfermeiras, indistintamente, perguntam sobre o ressecamento da mucosa [vaginal] e ao sentimento de dor na relação [sexual]. Interessante observar, no entanto, que independentemente da generalização tácita que as enfermeiras fazem a partir das (supostas) queixas das usuárias com base em suas faixas etárias - mulheres mais velhas sofrem de ressecamento vaginal e mulheres mais novas relacionam-se sexualmente com homens -, o uso de gel lubrificante é apresentado como solução indistinta em todos os casos. O Excerto 4 apresenta parte de uma interação em que se percebe a justaposição das questões supramencionadas:

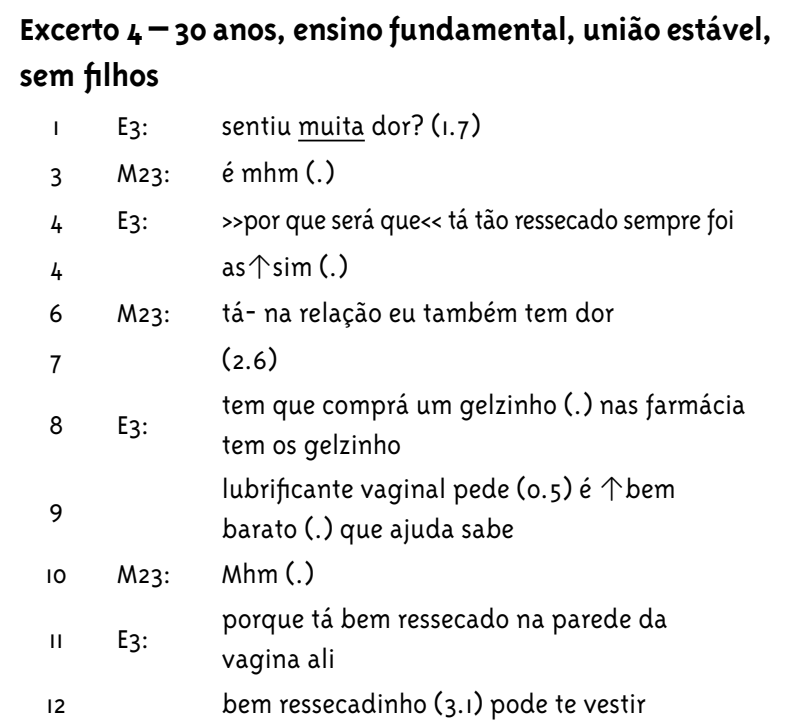

No excerto 4, a usuária (M23), ao ser questionada sobre ocorrência de dor no exame ginecológico, responde afirmativamente. A enfermeira, então, inicia a produção de um turno em formato de pergunta ("por que será que"), mas o abandona em prol da produção de uma avaliação ("tá tãao ressecado") e, em seguida, solicita informação da regularidade da condição observada. M23 não fornece a informação requerida, mas, em lugar disso, ela informa E3 de que há ocorrência de dor também em condição de atividade sexual (linha 6). Em oposição à adoção de uma postura investigativa do motivo da dor relatada pela usuária, E3 faz uma recomendação ("tem que compra um gelzinho" (linha 8), seguida da informação sobre onde encontrar o produto recomendado ("nas farmácia") e da avaliação de seu custo ("é bem barato", linha 9). O caráter tentativo da recomendação do uso de gel lubrificante como solução para a queixa de M23 é respondido por ela com provimento de resposta mínima (" $m h m$ ", linha 10). Desse modo, M23 demonstra que ouviu a recomendação sem se engajar de modo agentivo (Enfield; Sidnell, 2017), aceitando ou refutando a oferta. Cabe ressaltar que frente a uma prescrição e ou/recomendação do profissional, a resposta preferencial do/a usuário é a aceitação, devido à posição hierárquica na relação e ao trabalho 
interacional que precisa ser feito quando há uma recusa, que é maior no caso de um confronto com a autoridade presente na relação com o médico ou com a enfermeira, que funcionam como porta-vozes da instituição.

A lubrificação vaginal durante a atividade sexual das usuárias emerge nos dados como uma preocupação profissional frequente. No excerto 5 , a enfermeira referida como E1 inicia a sequência de abordagem desse tópico por meio de um turno de fala que opera como um preâmbulo ("e deixa eu te perguntá uma coisa") para a produção de uma pergunta, nesse caso, um pedido de informação acerca do desejo sexual de M1 ("tu tem vontade de ter relação", linha 1). $\mathrm{O}$ fato de a pergunta ter sido produzida dessa forma sinaliza que a enfermeira se orientou para o tema considerando-o delicado (Ostermann; Rosa, 2012), pedindo permissão para falar sobre a vida sexual da usuária. Veja-se o Excerto 5.

A ausência de resposta por parte de Mi à pergunta da enfermeira a mobiliza para prover um account ou uma justificativa, relacionando o desejo sexual com a lubrificação [da vagina] (linhas 3 e 4). A usuária afirma sentir desejo sexual, mas sua hesitação em responder e também os reparos que faz da própria fala (linhas 14 e 15) deixam transparecer a delicadeza que ela atribui ao tópico em pauta na conversa. Embora afirme a existência de lubrificação no ato sexual (linha 10), M1 admite não sentir desejo no ato sexual "às vezes" (linhas 7 a 9). Ela informa à enfermeira sobre suas estratégias para lidar com ausência de libido, quais sejam, "virar/fazer [sexo] de ladinho" (linhas g e 10) e "ficar mole" (linha 12). 0 uso do presente do indicativo ("eu viro", "a gente faz") sugere que o uso das referidas estratégias se dá de maneira corriqueira dentro da relação conjugal de Mi.

\section{Excerto 5- 37 anos, ensino superior incompleto, união estável, I filho}

\begin{tabular}{|c|c|c|}
\hline I & El: & $\begin{array}{l}\text { tá e deixa eu te perguntá uma coisa tu tem } \\
\text { vontade de ter relação }\end{array}$ \\
\hline 2 & & $(0.6)$ \\
\hline 3 & El: & >>porque $<<$ tem muito essa questão assim a \\
\hline 4 & & lubrifica[ção] \\
\hline 5 & MI: & [não] eu sei [eu sei] \\
\hline 6 & El: & [tu tem] a vontade (.) \\
\hline 7 & MI: & Ahã (.) às vezes eu [não]= \\
\hline
\end{tabular}

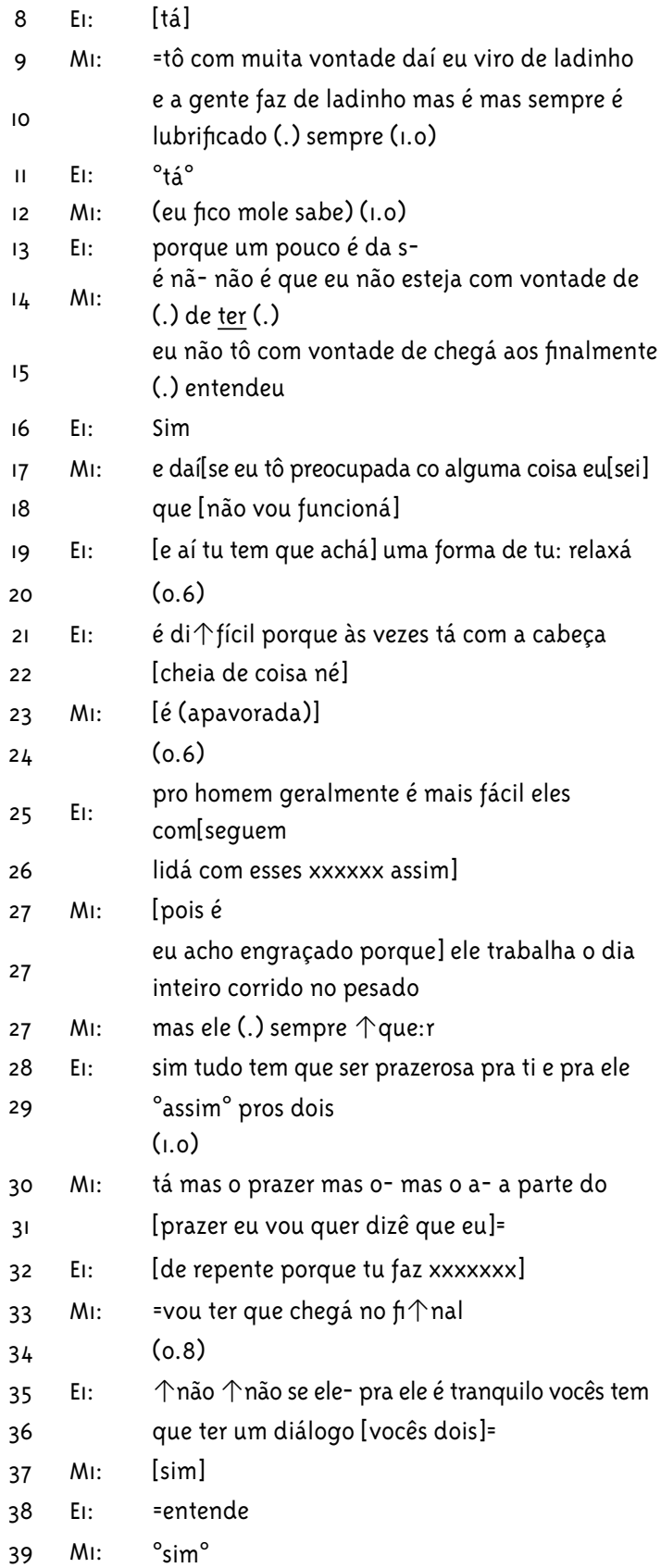

Entende-se que a prática das estratégias referidas local e situadamente por M1, para lidar com a falta de libido, pode ser pensada à luz da naturalização do papel feminino e das obrigações matrimoniais em que a mulher não está em posição de dizer "não" diante da necessidade sexual do marido. Ao que parece, a enfermeira se orienta para a naturalização dos direitos e obrigações generificados de maneira ambígua. Por um lado, E1 demonstra afiliação (Steensig; Larsen, 2008) com o ponto de vista de que é dever da mulher/esposa 
ceder ao ímpeto sexual do homem/marido (linha 19). Por outro lado, ela problematiza a informação recebida, na medida em que avalia que a relação sexual "tem que ser prazerosa pra ti e pra ele assim ${ }^{\circ}$ pros dois" (linhas 28 e 29). Apesar de certa ambivalência de E1 a respeito de a quem pertence o direito ao prazer sexual de modo primordial, vê-se que ela demonstra pender para a ratificação da naturalização das atribuições sociais generificadas em termos de relações de conjugalidade. Isso se torna evidente, por exemplo, na linha 25 , em que ela avalia ser mais fácil para os homens a atividade sexual, e na linha 35, em que ela condiciona à aceitação do homem/marido a decisão da mulher desejar "chegar [ou não] aos finalmentes”, isto é, atingir o orgasmo.

A desconsideração da enfermeira acerca dos problemas de ordem social e das hierarquias de gênero trabalha tacitamente em favor da reafirmação de ideias preconcebidas acerca da obrigatoriedade da mulher em prestar serviços sexuais ao marido, a despeito de sua vontade e satisfação sexual, inclusive suportando sentimento de dor e fingindo orgasmos.

Dentre os estereótipos de gênero veiculados na cultura e reafirmados nas consultas, enfermeira e usuária, nos excertos 5 e 6, compartilharam a concepção de uma masculinidade ancorada no biológico e, portanto, natural, segundo a qual a atividade sexual é um ímpeto do homem que as mulheres devem aceitar e satisfazer.

No Excerto 6, a enfermeira, referida como E1, inicia uma sequência de pedido de confirmação com foco na queixa de dor, feita pela usuária nomeada como M5, em situação de atividade sexual. Em resposta, $\mathrm{M}_{5}$ produz uma justificativa em que a dor, o desconforto e a falta de libido são relatados em um turno multiparte alongado e com evidente carga interacional, isto é, entremeado de pausas e hesitações, tanto em termos de escolhas lexicais, quanto de abandonos e recomeços (linhas 5 a 9). 0 formato que a resposta de $\mathrm{M}_{5}$ assume sugere que ela trata o tópico em pauta (dor na relação sexual) como delicado. Além disso, percebe-se que a usuária, após informar a enfermeira de que a dor se dá durante a relação sexual, realiza uma atribuição causal ou uma hipótese sobre a etiologia do problema (Ostermann; Souza, 2009), para o sentimento de desconforto. Assim, M5, com base em uma voz de autoridade ("o doutor falou", linha 11), atribui à dor uma causa físico-anatômica ("bexiga caída”, linha 12). Dessa forma, ela afasta a possibilidade de a dor ter como causa algum fator externo (e.g., alguma ação realizada pelo companheiro).

A enfermeira persevera na investigação afunilando a pergunta: "mesmo com dor tu tem relação" (linha 16), ao que $\mathrm{M}_{5}$ responde afirmativamente, porém mitigando a frequência da dor com base na justificativa de que sua ocorrência é descontinuada. Diante das revelações de M5 sobre desconfortos esporádicos nas relações sexuais, E1 questiona a qualidade das relações de M5 e solicita informação sobre ocorrência ou não de lubrificação vaginal durante a atividade sexual. A usuária abstém-se de tomar o turno depois do pedido de informação sobre lubrificação, o que fica evidente pela pausa transcrita na linha 24. A enfermeira, então, refaz o pedido de informação (linha 25). A pausa e a repetição parcial do pedido de informação indicam quebra do fluxo da conversa e, portanto, problema interacional, que se confirma com o reparo de entendimento iniciado pela usuária, na linha 26 ("como assim") e levado a cabo pela enfermeira (linhas 27 e 28). De acordo com Schegloff, Jefferson e Sacks (1977), conforme previamente mencionado, um reparo é a situação em que os participantes da conversa interrompem a interação para esclarecer mal-entendidos da ordem da fala, da audição ou do entendimento. Percebe-se que a sequência de reparo ocorrida na interação em análise auxilia M5 a fazer sentido da informação buscada por E1, tanto que a usuária elabora a resposta sobre o tópico abordado pela enfermeira, qual seja, lubrificação [vaginal], mais especificamente, a descontinuidade de sua intercorrência.

\begin{tabular}{|c|c|c|}
\hline 1 & El: & $\begin{array}{l}\text { tu me falou dos sintomas que tu tá e que tu } \\
\text { tem- tu tem dor né }\end{array}$ \\
\hline 3 & M5: & [tenho] \\
\hline 4 & El: & [dor] durante a rela $\uparrow c ̧ a ̃ o$ \\
\hline 5 & M5: & é não é sempre eu não sei como é que é isso assim \\
\hline 6 & & é parece que tem dias que é uma coisa que (.) \\
\hline 7 & & $\begin{array}{l}\text { tudo bem (0.5) mas tem dia assim que parece } \\
\text { que n: }\end{array}$ \\
\hline 8 & & é uma coisa desconfortável assim não não:: \\
\hline 9 & & $(6.8)$ \\
\hline 10 & El: & é durante e depois ou só duran[te] \\
\hline II & M5: & [sim] e aí depois eu não sei porque o doutor \\
\hline 12 & & falou que eu tinha a minha bexiga caída (0.7) \\
\hline
\end{tabular}




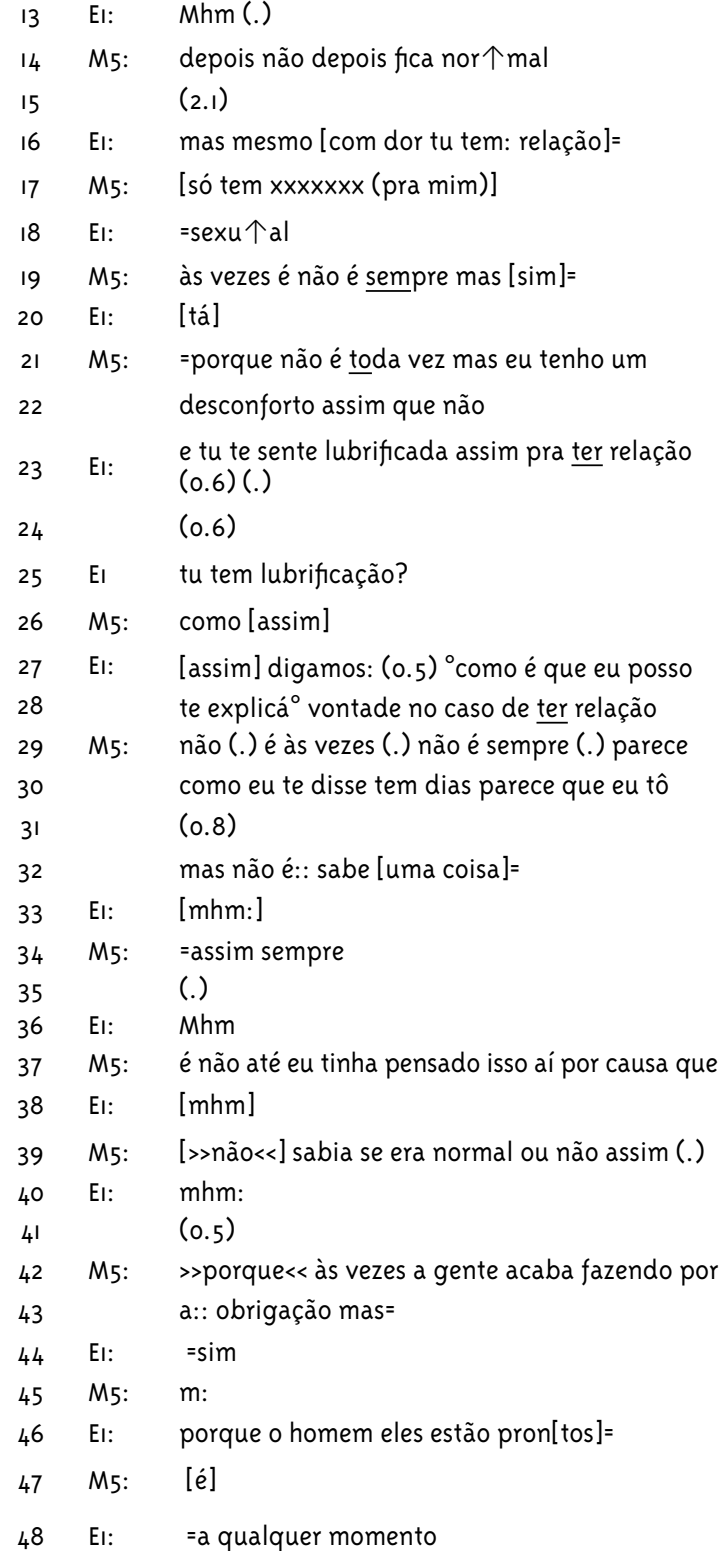

Cabe reparar que não ter lubrificação e não sentir vontade de fazer sexo são tratados como problemáticos pela usuária, que realiza um trabalho interacional (linhas 29 a 39) com recomeços, micropausas, pausa intraturno e hesitação, alternâncias entre negativa ("não") e prevalência ("às vezes"; "não é sempre") de prazer na relação, situação que ela afirma não ter certeza ser normal ou não (linha 39).

Com base no Excerto 6, embora seja notável que o prazer sexual da usuária esteja na agenda profissional da enfermeira, vale pontuar que ambas as mulheres enfermeira e usuária: (1) tratam a ausência de libido como questão unilateral; (2) concebem a atividade sexual como obrigação feminina dentro da relação de conjugalidade ("porque às vezes a gente acaba fazendo [sexo] por obrigação", linhas 42 e 43); (3) percebem o ímpeto sexual masculino como natural ("os homens estão sempre prontos [para o sexo]", linhas 46 a 48). A naturalização da atividade sexual como prática cotidiana incontestável também pode ser verificada nos dados, conforme a interação apresentada no Excerto 7:

\section{Excerto 7 - 40 anos, ensino médio incompleto, solteira, 3 filhos \\ l M9: então eu não sei mais o que que é viver sem dor \\ 2 tipo até de $\uparrow$ noite quando eu viro na cama \\ 3 virá de um lado pro outro > parece< que rasga por \\ 4 dentro [assim sabe] \\ 5 E2: [dói] \\ 6 M9: $M h m$ \\ $7 \quad(0.8)$ \\ 8 M9: e a relação também não tem como eu acho \\ M9: que deve \\ 9 ter ficado tudo né \\ 10 E2: mas é mu:ito desconforto ou é um desconforto \\ II tolerável assim \\ $12 \quad(1.0)$ \\ 13 E2: na relação sexual \\ $14 \quad$ (1.5) \\ 15 M9: tem dias que não dá né que é insuportável e tem \\ 16 outros que é menos tem dias que não dói (.) \\ 17 entendeu é uma coisa as[sim] \\ 18 E2: [é]}

No excerto 7, M9 informa E2 que não sabe mais viver sem dor. Observa-se que a usuária seleciona o contexto noturno e o local da cama para descrever a dor que a atormenta ("uma dor que rasga por dentro", linhas 3 e 4). A enfermeira realiza um trabalho de afunilamento para explorar a queixa de dor da usuária, solicitando à M9 que identifique a intensidade do desconforto de acordo com as alternativas providas por ela, ou seja, "mu:ito desconforto" (note-se o prolongamento da palavra muito) ou "um desconforto tolerável assim" (linhas 10 e 11). A usuária demonstra 
dificuldade em selecionar uma das alternativas propostas, haja vista o atraso de sua resposta (linha 12). E2, então, especifica o contexto de ocorrência da dor, isto é, "na relação sexual" (linha 13). Após mais uma pausa, considerada interacionalmente longa (linha 14), M9 começa a elaborar sua resposta. $O$ início do turno multiparte de M9 é reservado para negar a regularidade da atividade sexual por meio de uma solicitação de concordância que, ao que parece, busca por afiliação - nesse sentido, note-se que a primeira parte do turno multiparte termina com a partícula "nê" (“tem dias que não dá nể, linha 15), o que imprime um apelo por aquiescência à ideia proposta naquela parte do turno e, ao mesmo tempo, por empatia em relação à experiência da dor enquanto fator limitante para a relação sexual e que, portanto, torna-se "insuportável" (linha 15). O conteúdo restante do turno de M9 permite inferir que a usuária, apesar de nunca afirmar com absoluta transparência, também mantém relações sexuais nas situações em que há ausência de dor.

O que chama atenção nesse excerto é o fato de que a manutenção de relações sexuais é tratada pelas participantes como algo dado, isto é, uma atividade cotidiana com ocorrência mesmo em situações de sofrimento físico. Esse fato adquire maior gravidade na medida em que as disfunções sexuais femininas são descritas na literatura médica como agravo de elevada prevalência (Faubion; Rullo, 2015; Lara et al., 2008).

Esta pesquisa permitiu observar no espaço da consulta ginecológica e nas conversas entre enfermeiras e usuárias, o compartilhamento de categorias de pertença pautadas nos moldes tradicionais, incluindo a posição subalterna da mulher na sociedade ("ser mulher é um saco"), a centralidade e o sofrimento da maternidade (" $a$ posição de ganhar nenê, aquela que não dá para esquecer"), a prestação de serviços sexuais aos maridos ("sexo por obrigação"), as dificuldades de ter prazer sexual em contextos de obrigatoriedade, desconforto e dor ("a dor que rasga por dentro") e a identidade de gênero naturalizada do homem ("sempre pronto para o sexo").

Nessas conversas, a sexualidade feminina está pautada nos (velhos) estereótipos de gênero que seguem vigentes nas falas de profissionais e usuárias dos serviços de saúde, naturalizados e aceitos mesmo quando há algum questionamento, constituindo a ideologia que cimenta as hierarquias entre os sexos e que, como salienta Butler (2007), na maioria das vezes não é percebida pelos interagentes.

Desse modo, as identidades femininas dessas mulheres de um município de médio porte do interior do Rio Grande do Sul são ainda construídas e constituídas por meio das funções e papéis ligados à família, incluindo os deveres conjugais e da maternidade, desempenhados de modo subordinado ao masculino.

\section{Considerações finais}

Nas consultas ginecológicas de enfermagem para a realização de coleta de material destinado a exame citopatológico que fizeram parte desta pesquisa, mulheres usuárias e enfermeiras compartilham ideias pautadas na heteronormatividade sobre as identidades masculinas e femininas, em que a sexualidade dos homens, pautada no biológico, é irreprimível, e elas "têm" que se comportar de acordo com os papéis designados ao feminino. Elas fazem sexo para atender à necessidade sexual de maridos e companheiros e, no modo com que foram socializadas, construíram suas identidades e continuam se pautando, o sexo é uma obrigação. As enfermeiras falam de mucosas ressecadas e oferecem gel lubrificante, um paliativo para amenizar as situações em que o sexo é uma imposição e uma obrigação e a medicalização da sexualidade evita o questionamento dos padrões normativos e patriarcais.

Ainda são poucos os trabalhos no Brasil que utilizam a fala-em-interação, inclusive em pesquisas sobre a relação dialógica de conversas entre profissionais de saúde e mulheres (Andrade, 2016), embora a dimensão relacional do encontro que acontece nas consultas constitua um elemento central na prestação do cuidado em saúde.

Este texto se inspira nos pressupostos da análise da fala-em-interação e em alguns elementos linguísticos, sem a pretensão de esgotar as possibilidades de análise e interpretação do material empírico, o que pode significar uma limitação deste estudo. Porém, espera-se que estes achados possam gerar alguma contribuição para melhorar a comunicação entre profissionais de saúde e 
usuárias, evitando situações conversacionais que possam gerar mal-estar e/ou validar padrões e estereótipos que afirmam a hierarquia entre os sexos e a submissão feminina.

\section{Referências}

ALVES, P. C.; RABELO, M. Experiência de doença e narrativa. Rio de Janeiro: Ed. Fiocruz, 1999.

ANDRADE, D. N. P. Recomendações e prescrições para o cuidado de saúde no pós-alta: investigação de um programa educativo a pacientes cardiopatas sob uma perspectiva interacional. 2016. Tese (Doutorado em Linguística Aplicada) - Universidade do Vale do Rio dos Sinos, São Leopoldo, 2016.

BRAGA, A.; GASTALDO, E.; GUIMARÃES, J. D. A. Análise de categorizações de pertencimento nos estudos de comunicação: um ensaio de metodologia aplicada. Brazilian Journalist Research, Brasília, DF, v. 12, n. 2, p. 198-213, 2016.

BRASIL. Ministério da Saúde. Saúde sexuale saúde reprodutiva. Brasília, DF, 2013. (Cadernos de Atenção Básica, n. 26).

BUTLER, J. El género em disputa: el feminismo y la subversión de la identidad. Barcelona: Paidós, 2007.

CAMERON, D. Gender, language, and discourse: a review essay. Signs, Chicago, v. 23, n. 4, p. 945970, 1998.

CAMERON, D. Language, gender and sexuality: current issues and new directions. Applied Linguistics, Oxford, v. 26, n. 4, p. 482-502, 2005.

CAPRARA, A.; RODRIGUES, J. A relação assimétrica médico-paciente: repensando o vínculo terapêutico. Ciência e Saúde Coletiva, Rio de Janeiro, v. 9, n. 1, p. 139-146, 2004.

CORONA, M.; OSTERMANN, A. C. Formulação de lugar, intersubjetividade e categorias de pertença em chamadas de emergência para o 190. Linguística Aplicada das Profissões, Juiz de Fora, v. 16. n. 1, p. 112-129, 2012.

ENFIELD, N. J.; SIDNELL, J. The concept of action. Cambridge: Cambridge University Press, 2017.
FAUBION, S. S.; RULLO, J. E. Disfunção sexual na mulher: uma abordagem prática. Revista Portuguesa de Medicina Geral e Familiar, Lisboa, v. 31, n. 5, p. 351-353, 2015.

GAGO, P. C. Questões de transcrição em análise da conversa. Veredas, Juiz de Fora, v. 6, n. 2, p. 89-113, 2002.

LARA, L. A. S. et al. Abordagem das disfunções sexuais femininas. Revista Brasileira de Ginecologia e Obstetrícia, Ribeirão Preto, v. 30, n. 6, p. 312-321, 2008.

LODER, L. L.; JUNG, N. M. (Org.). Análises de fala-em-interação institucional: a perspectiva da análise da conversa etnometodológica. Campinas: Mercado de Letras, 2009.

MENEGHEL, S. N.; OSTERMANN, A. C. E então, quais as contribuições dos estudos da fala-em-interação para a atenção à saúde? In: OSTERMANN, A. C.; MENEGHEL, S. N. (Org.). Humanização, gênero, poder: contribuições dos estudos de fala-em-interação para a atenção à saúde. Rio de Janeiro: Fiocruz; Campinas: Mercado de Letras, 2012. p. 153-161.

OSTERMANN, A. C. Comunidades de prática: gênero, trabalho e face. In: HEBERLE, V. M.; OSTERMANN, A. C.; FIGUEIREDO, D. C. (Org.). Linguagem e gênero no trabalho, na mídia e em outros contextos. Florianópolis: Editora UFSC, 2006. p. 15-47.

OSTERMANN, A. C.; JAGER, A. Gênero e sexualidade, o consultório ginecológico: pressupostos identitários jamais questionados. In: OSTERMANN, A. C.; MENEGHEL, S. N. (Org.). Humanização, gênero, poder: contribuições dos estudos da fala-em-interação para a atenção em saúde. Rio de Janeiro: Fiocruz; Campinas: Mercado de Letras, 2012. p. 119-132.

OSTERMANN, A. C.; MENEGHEL, S. N. (Org.). Humanização, gênero, poder: contribuições dos estudos de fala-em-interação para a atenção à saúde. Rio de Janeiro: Fiocruz; Campinas: Mercado de Letras, 2012.

OSTERMANN, A. C.; ROSA, D. R. Do que não se fala: assuntos tabus e momentos delicados 
em consultas ginecológicas e obstétricas. In: OSTERMANN, A. C.; MENEGHEL, S. N. (Org.). Humanização, gênero, poder: contribuições dos estudos da fala-em-interação para a atenção em saúde. Rio de Janeiro: Fiocruz; Campinas: Mercado de Letras, 2012. p. 47-64.

OSTERMANN, A. C.; SOUZA, J. Contribuições da análise da conversa para os estudos sobre o cuidado em saúde: reflexões a partir das atribuições feitas por pacientes. Cadernos de Saúde Pública, Rio de Janeiro, v. 25, n. 7, p. 15211533, 2009.

PINTO, J. P.; BADAN, S. C. Feminismo e as identidades no cerne dos princípios de pesquisa. Calidoscópio, v. 10, n. 2, p. 133-139, 2012.

POMERANTZ, A.; MANDELBAUM, J. Conversation analytic approaches to the relevance and uses of relationship categories in interaction. In: FITCH, K. L.; SANDERS, R. E. (Ed.). Handbook of language and social interaction. Mahwah: Lawrence Erlbaum, 2005. p. 149-171.

SCHEGLOFF, E. A. A tutorial on membership categorization. Journal of Pragmatics, Amsterdam, v. 39, n. 3, p. 462-482, 2007.

SCHEGLOFF, E. A.; JEFFERSON, G.; SACKS, H. The preference for self-correction in the organization of repair in conversation. Language, Washington, DC, v. 53, n. 2, p. 361-382, 1977.

SCHRAIBER, L. B. No encontro da técnica com a ética: o exercício de julgar e decidir no cotidiano do trabalho em medicina. Interface, Botucatu, v. 1, n. 1, p. 123-138, 1997.

SCOTT, J. Gênero: uma categoria útil de análise histórica. Educação e Realidade, Porto Alegre, v. 16, n. 2, p. 5-22, 1990.

SELL, M. Significando o abuso sexual infantil na fala em interação: estratégias interacionais acionadas por conselheiros tutelares e crianças na reconstrução da narrativa do abuso. 2012. Tese (Doutorado em Linguística Aplicada) Universidade do Vale do Rio dos Sinos, São Leopoldo, 2012.
SELL, M.; OSTERMANN, A. C. Análise de categorias de pertença (ACP) em estudos de linguagem e gênero: a (des)construção discursiva do homogêneo masculino. Alfa, Araraquara, v. 53, n. 1, p. 11-34, 2009.

SELL, M.; OSTERMANN, A. C. Tensionando identidades de gênero e de sexualidade na fala em interação: o colapso discursivo da masculinidade hegemônica. In: OSTERMANN, A. C.; MENEGHEL, S. N. (Org.). Humanização, gênero, poder: contribuições dos estudos da fala-em-interação para a atenção em saúde. Rio de Janeiro: Fiocruz; Campinas: Mercado de Letras, 2012. p. 133-149.

SILVA, C. A.; ANDRADE, D. N. P.; OSTERMANN, A. C. Análise da conversa: uma breve introdução. Revista Virtual de Estudos da Linguagem, [s.l.], v. 7, n. 13, p. 1-21, 2009.

SILVA, M. M.; GITSOS, J.; SANTOS, N. L. P. Atenção básica em saúde: prevenção do câncer de colo do útero na consulta de enfermagem. Revista de Enfermagem UERJ, Rio de Janeiro, v. 2, p. 631636, 2013. Número especial 1.

SOUZA, J. Do prescrito ao realizado: as demandas interacionais das ligações para o Disque Saúde Mulher e sua relação com as instancias de prescrição do trabalho de atender. 2009. Dissertação (Mestrado em Linguística Aplicada) - Universidade do Vale do Rio dos Sinos, São Leopoldo, 2009.

STEENSIG, J.; LARSEN, T. Affiliative and disaffiliative uses of you say $\mathrm{x}$ question.

Discourse Studies, Thousand Oaks, v. 10, n. 1, p. 113-133, 2008.

WATSON, R.; GASTALDO, E. Etnometodologia e análise da conversa. Rio de Janeiro: Editora PUC Rio: Vozes, 2015.

\section{Contribuição dos autores}

Ambas as autoras participaram de todas as etapas de elaboração do artigo, Andrade mais especificamente na análise linguística.

Recebido: 09/11/2018

Aprovado: 22/01/2019 